\title{
Experimental Investigation of Phase Change inside a Finned-Tube Heat Exchanger
}

\author{
M. Rahimi, ${ }^{1}$ A. A. Ranjbar, ${ }^{1}$ D. D. Ganji, ${ }^{1}$ K. Sedighi, ${ }^{1}$ and M. J. Hosseini ${ }^{2}$ \\ ${ }^{1}$ School of Mechanical Engineering, Babol University of Technology, P.O. Box 484, Babol 4714871167, Iran \\ ${ }^{2}$ Department of Mechanical Engineering, Golestan University, P.O. Box 155, Gorgan 4913815739, Iran
}

Correspondence should be addressed to M. Rahimi; m.rahimi.m.85@gmail.com

Received 26 May 2014; Revised 13 September 2014; Accepted 14 September 2014; Published 8 October 2014

Academic Editor: Shuisheng He

Copyright (c) 2014 M. Rahimi et al. This is an open access article distributed under the Creative Commons Attribution License, which permits unrestricted use, distribution, and reproduction in any medium, provided the original work is properly cited.

\begin{abstract}
An experimental study is conducted in order to investigate melting and solidification processes of paraffin RT35 as phase change materials in a finned-tube. Therefore the effect of using fins in this study as well as some operational parameters is considered. The motivation of this study is to design and construct a novel storage unit and to compare it with a finless heat exchanger. A series of experiments are conducted to investigate the effect of increasing the inlet temperature and flow rate on the charging and discharging processes of the phase change material. It is shown that, using fins in phase change process enhances melting and solidification procedures. The trend of this variation is different for the heat exchangers; increasing the inlet temperature for the bare tube heat exchanger more effectively lowers melting time. Similarly, flow rate variation varies the solidification time more intensely for the bare tube heat exchanger.
\end{abstract}

\section{Introduction}

In light of the availability of considerable latent heat of fusion upon melting and solidification (freezing), phase change materials (PCM) have long been used for thermal energy storage applications including waste heat recovery, thermal management of electronics, and solar thermal energy utilization. The main advantage of these systems is their ability to store a large amount of energy in a relatively small volume at a constant phase change temperature. Thus, many authors have reported the results of researches on PCM thermal storage during melting and solidification processes in energy storage systems.

In thermal storage systems low conductivity of different PCMs is a disadvantage, since the adequate amount of energy capacity may be available but the system may not be able to use it at the desired rate. Regarding the defect of low thermal PCMs conductivity, several ideas and innovations have been proposed in the literature to enhance heat transfer for which the effects and consequences are studied both numerically and experimentally.
Employing finned-tubes with different configurations [19] and adding particles with higher thermal conductivity than the PCM $[1,10-19]$ enhance the effective thermal conductivity of PCM used in PCM-based thermal systems.

Hosseini et al. [20] experimentally and numerically studied the effects of natural convection during melting of a paraffin wax in a shell and tube heat exchanger. They found that the melting front appeared at different times at positions close to the HTF (heat transfer fluid) tube and progressed at different rates outwards, toward the shell. They concluded that, by increasing the inlet water temperature from $70^{\circ} \mathrm{C}$ to $80^{\circ} \mathrm{C}$, the total melting time decreases to $37 \%$.

Agyenim et al. [21-24] investigated melting and solidification of a paraffin in a shell and tube heat exchanger with the HTF circulating inside the tube and the PCM filling the shell side, for various operating conditions and geometric parameters.

Experimental study on the solidification of water in annular geometry was first considered by Sinha and Gupta [25]. In this work the horizontal arrangement of an isothermal copper tube with isolated external glass tube was used. Results 
are presented for different values of wall temperature and initial water temperature. Their result was compared with the experimental measurements and a good agreement was observed.

Ezan et al. [26] experimentally studied charging and discharging periods of water in a shell and tube system. They investigated the effect of flow rate, inlet temperature, thermal conductivity of the tube material, and shell diameter on the storage capability of the system. Results indicated that, for both solidification and melting processes, natural convection becomes the dominant heat transfer mechanism after a short heat conduction dominated period and, for discharging period, the inlet temperature of HTF is more effective on rejected energy in comparison with the flow rate, for selected parameters.

Medrano et al. [27] have experimentally evaluated heat transfer characterization of various small PCM storage systems during the melting and solidification processes in order to assess their potential implementation in small-sized systems. Results also showed that a heat exchanger including PCM embedded in a graphite matrix has a higher heat transfer coefficient $\left(700-800 \mathrm{~W} / \mathrm{m}^{2} \mathrm{~K}\right)$.

Furthermore, Akgun et al. [28, 29] experimentally investigated the melting and solidification processes of a paraffin as a PCM in a novel tube in a shell heat exchanger system. Their heat exchanger is a vertical shell and tube one in which inlet temperature and flow rate are studied. They showed that, unlike inlet temperature, flow rate has negligible effect on melting time [28]. They also studied the effect of inclination angle of the shell [29]. Their result showed that this parameter can reduce the melting time up to 30 percent.

Trp et al. $[6,7]$ investigated melting and solidification on a paraffin in a shell and tube heat exchanger with the HTF circulating inside the tube and the PCM filling the shell side, for various operating conditions and geometric parameters.

Zeng et al. [30] investigated the effect of containing Ag nanoparticles on the thermal conductivity of the composite PCM. An increase in thermal conductivity is observed as the nanoparticles are loaded.

Ranjbar et al. [31] investigated the influence of utilizing nanoparticle on enhancement of heat transfer in a threedimensional cavity. Their results indicated that the suspended nanoparticles increase the heat transfer rate.

Natural convection of mixture of nanoparticles and water near its maximum density in a rectangular enclosure was studied by Rahimi et al. [32]. Their result showed that heat transfer rate considering a non-Boussinesq temperaturedependent density (inversion of density) exhibits a nonlinear behavior with changes in nanoparticle volume fraction.

Ho and Gao [33] experimentally investigated the effects of inserting alumina $\left(\mathrm{Al}_{2} \mathrm{O}_{3}\right)$ nanoparticles in a paraffin (n-octadecane) on its thermophysical properties, including latent heat of fusion, density, dynamic viscosity, and thermal conductivity. They found that increasing the nanoparticles raises the conductivity nonlinearly while this increase for viscosity is more pronounced. They concluded that dispersing $\mathrm{Al}_{2} \mathrm{O}_{3}$ as nanoparticle diminishes convective heat transfer coefficient.
TABLE 1: Thermophysical properties of RT35.

\begin{tabular}{lc}
\hline Properties & Typical values \\
\hline$T_{\text {solid }}[\mathrm{K}]$ & 302 \\
$T_{\text {liquid }}[\mathrm{K}]$ & 308 \\
$\rho_{\text {solid }}\left[\mathrm{kg} / \mathrm{m}^{3}\right]$ & 860 \\
$\rho_{\text {liquid }}\left[\mathrm{kg} / \mathrm{m}^{3}\right]$ & 770 \\
$c_{P}[\mathrm{~J} / \mathrm{kg} \mathrm{K}]$ & 2000 \\
$k[\mathrm{~W} / \mathrm{m} \mathrm{K}]$ & 0.2 \\
$L[\mathrm{~J} / \mathrm{kg}]$ & 170000 \\
$\beta[1 / \mathrm{K}]$ & 0.0006 \\
\hline
\end{tabular}

Elgafy and Lafdi [34] prepared a composite with carbon nanofibers filled in with paraffin, and the results stated that the thermal conductivity of the nanopcm was enhanced significantly, which increased the cooling rate in the solidification process.

Mettawee and Assassa [35] experimentally investigated the enhancement in the performance of PCM-based solar collector due to the dispersion of micro aluminium particles. The results indicated that the charging time was decreased by $60 \%$ compared to that of pure PCM. The effect was more pronounced during discharging, as the conduction dominated solidification presented more homogeneous process.

Most of the mentioned studies have reported the investigation of melting and solidification on a PCM in a shell and tube heat exchanger. Provided utilizing finned-tube heat exchanger boosts the amount of transferred heat due to twisted tubes and their extended surfaces, the present study investigates improved thermal characteristic of a compact heat exchanger experimentally and compares the results with outcomes of corresponding bare tube heat exchanger for different inlet HTF temperature and flow rate.

\section{Experimental Setup and Procedure}

The test in Figure 1 loop consists of cold and hot water pumps, cold and hot water tanks, cooling units, the finned-tube heat exchanger as test section, a flow control system, and a measurement system.

The heat exchanger is made of the typical aluminum fins and copper tubes. It also includes a transparent plexiglass box which is filled with PCM in a way that the material is in the spaces between tubes and fins. The plexiglass shell thickness is $20 \mathrm{~mm}$. Copper tubes inner and outer diameters are $9 \mathrm{~mm}$ and $12.7 \mathrm{~mm}$, respectively. The fin pitch is depicted in Figure 2. The finned-tube heat exchanger includes 6 straight tubes in a row which are connected via u-bend. To minimize the heat losses and eliminate the worries of controlling the environment temperature to keep the tests homogenous, the test section was isolated thermally by glass wool of a $60 \mathrm{~mm}$ thickness.

The system consists of two fluid flow loops and a charging loop in which the HTF flows by forced convection through the HTF tubes during melting process. In this process, hot fluid heats the PCM which melts and stores the heat. During 

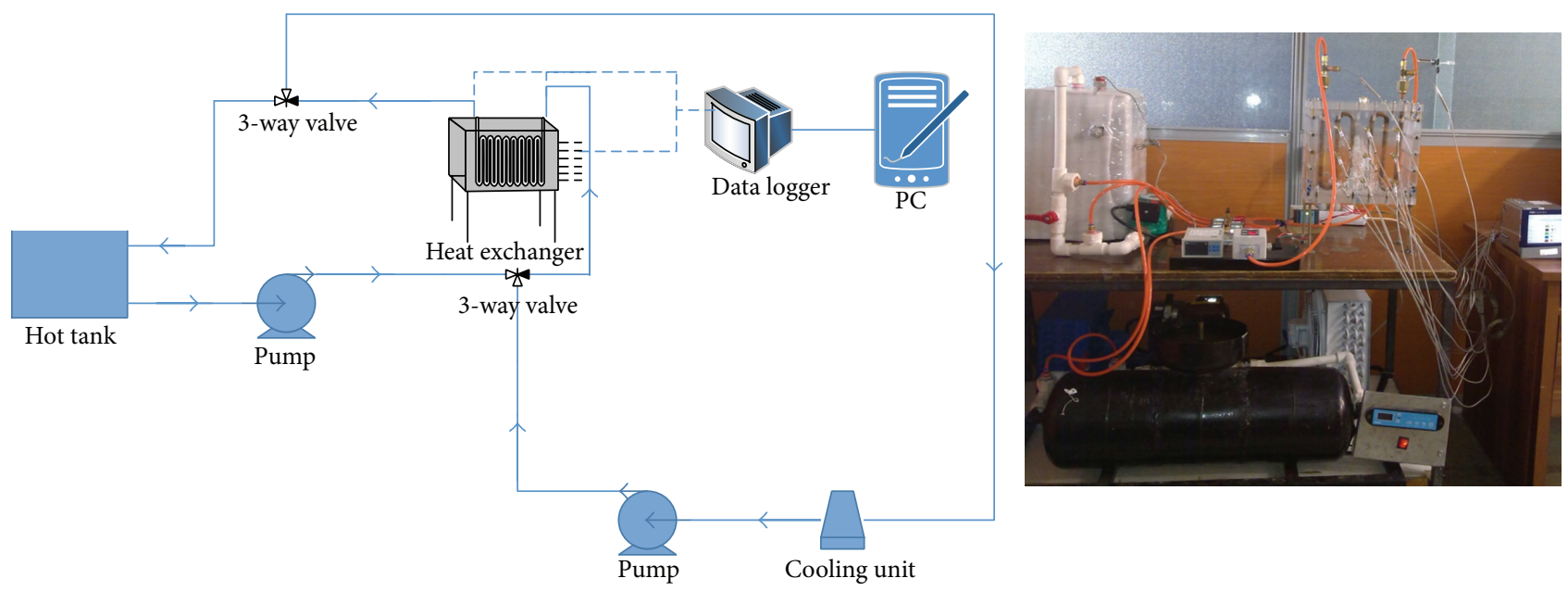

FIGURE 1: Schematic diagram and photograph of the experimental set-up.
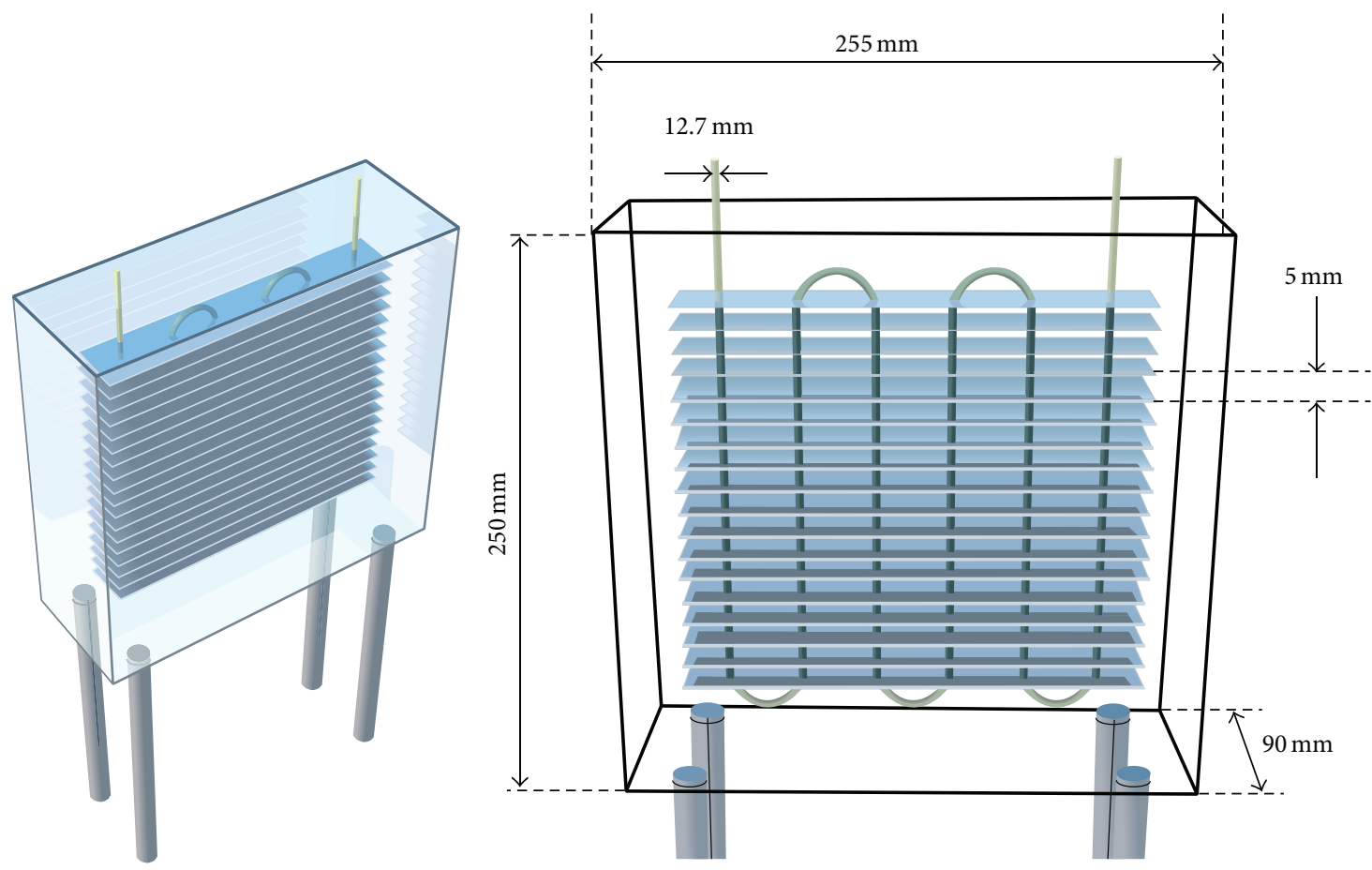

Figure 2: Schematic view of test section of finned-tube heat exchanger.

the solidification process, the PCM solidifies and the stored heat is delivered to the cold fluid in the tubes.

The inlet and outlet temperature of the HTF tube are measured by $2 \mathrm{~K}$-type thermocouples and the 12 sample points of PCM are chosen to record measured temperature values by $12 \mathrm{~K}$-type thermocouples inserted in the small sealed holes pierced on the shell of the heat exchanger. The temperature values are read through a Jumo data logger and recorded in a $\mathrm{PC}$.

The positions of inserted thermocouples are illustrated in Figure 3. As can be seen, the 12 thermocouples are categorized into 4 groups, $\mathrm{A}, \mathrm{B}, \mathrm{C}$, and $\mathrm{D}$, nine of which are at $45 \mathrm{~mm}$ depth (groups A, B, and C) and the 3 left, numbered 10, 11, and 12 , are located at $5 \mathrm{~mm}$ depth (group D).

2.1. Characterization of PCMs. In this work, commercial paraffin RT35 (Rubitherm $\mathrm{GmbH}$ ) is used as a latent heat energy storage material. RT35 is chemically stable, nonpoisonous, and noncorrosive over a large storage period and through the phase change cycles. Table 1 depicts the thermophysical properties of RT35.

2.2. Methodology of Tests. After the heat exchanger is filled up with liquid PCM and no leakage was observed, a charging experiment is started, with the solid PCM at thermal 

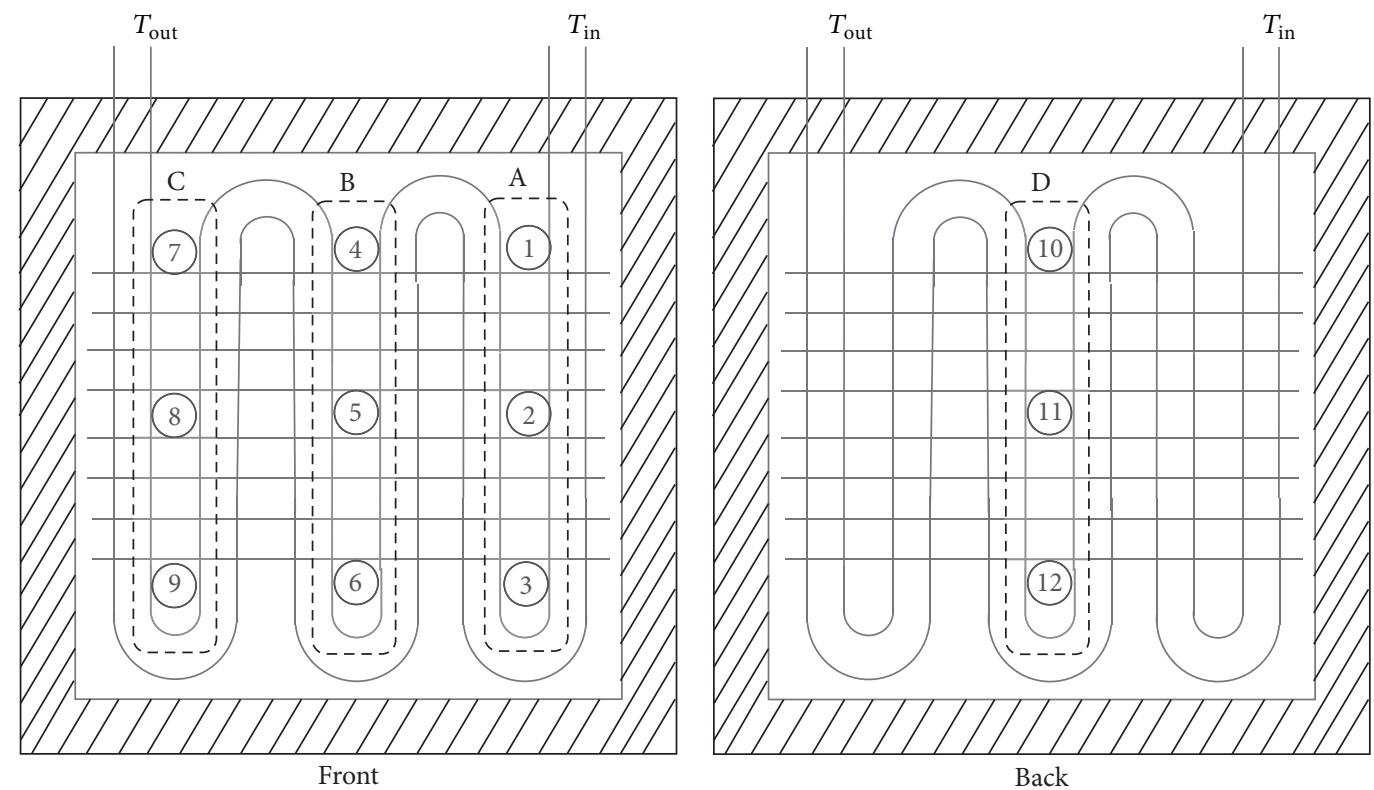

FIGURE 3: Location of thermocouple position in the control system.

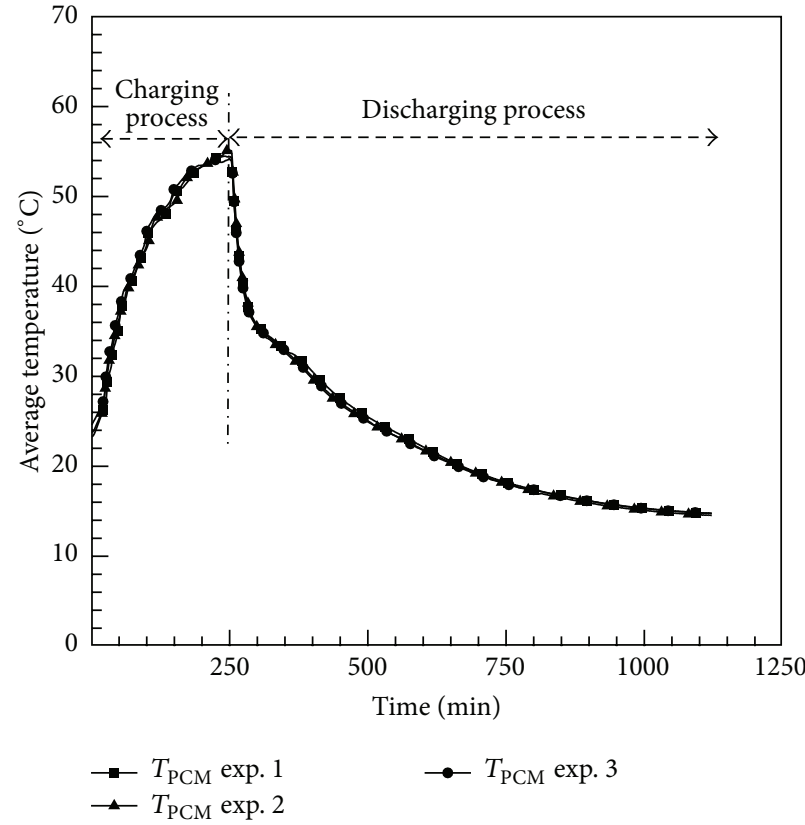

(a)

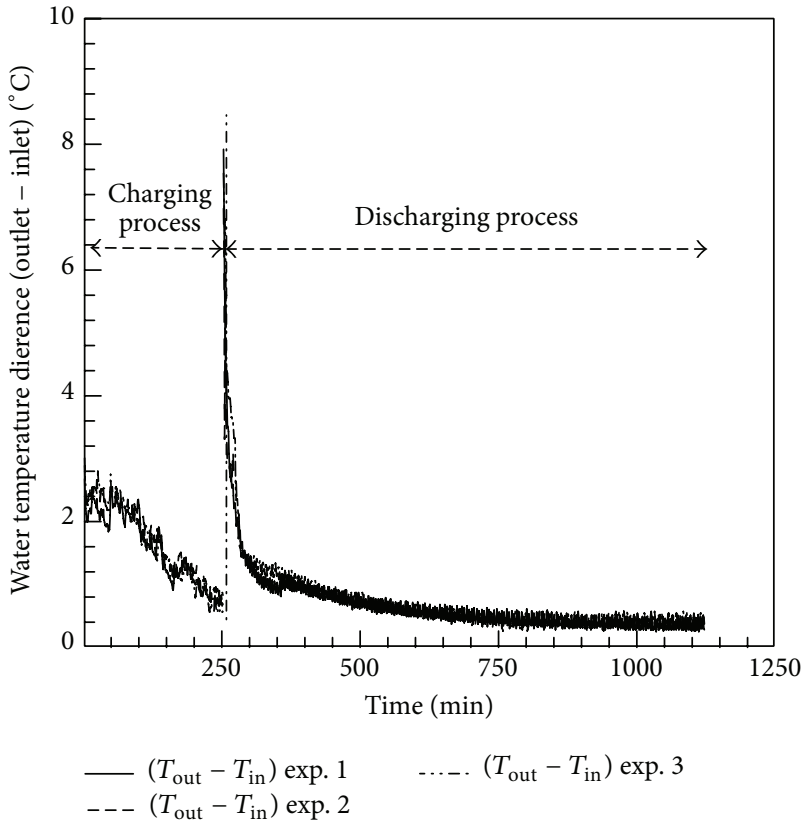

(b)

FIGURE 4: Repeatability of experimental results: (a) the average temperature profile in PCM; (b) water temperature difference (outlet - inlet).

equilibrium with the conditioned lab temperature $\left(21-24^{\circ} \mathrm{C}\right)$. Hot water from the hot bath is circulated through the heat exchanger tubes until no solid PCM is observed and the discharging part is started, just after the charging test is finished. Cold water from the cold bath is pumped to the heat exchanger whose shell is filled with PCM melt, which starts to solidify. Since, based on observations, the 11th thermocouple displays the highest temperature through the discharge process and the PCM melting range is $29-35^{\circ} \mathrm{C}$, $27^{\circ} \mathrm{C}$ of this instrument can be the termination criteria of the discharge process. Temperature readings are set to occur every 1 minute.

In this paper, the effect of changing the inlet HTF temperature and variation of flow rates on the melting and solidification process is investigated. The hot inlet temperatures for the charging test $\left(T_{H}\right)$ are $50^{\circ} \mathrm{C}, 60^{\circ} \mathrm{C}$, and $70^{\circ} \mathrm{C}$ and for discharging tests the cold inlet temperature $\left(T_{C}\right)$ is $10^{\circ} \mathrm{C}$. The flow rate for all varying temperatures is set 


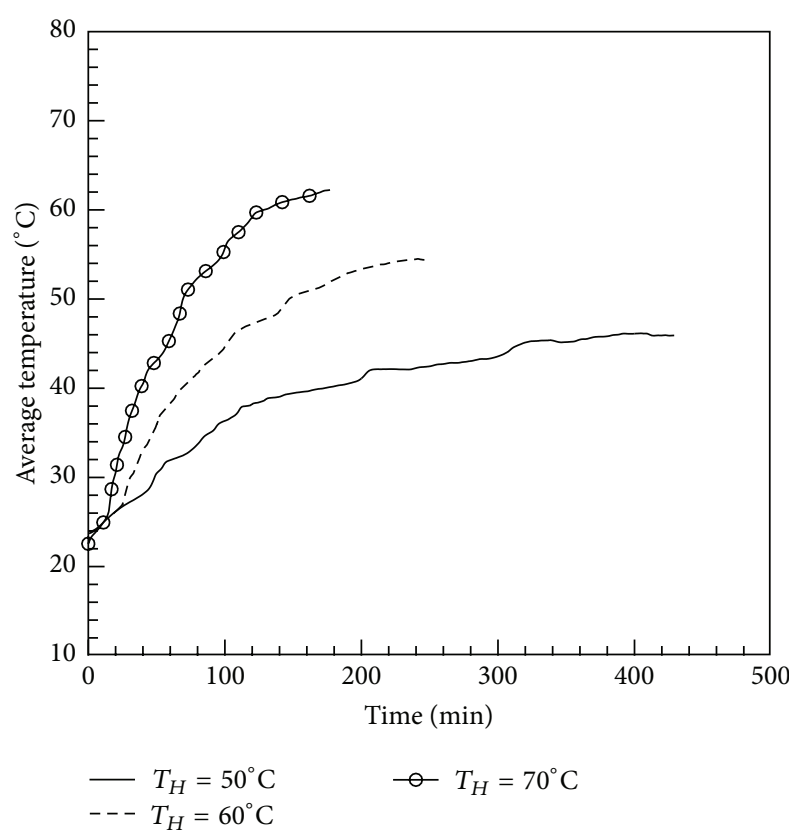

(a)

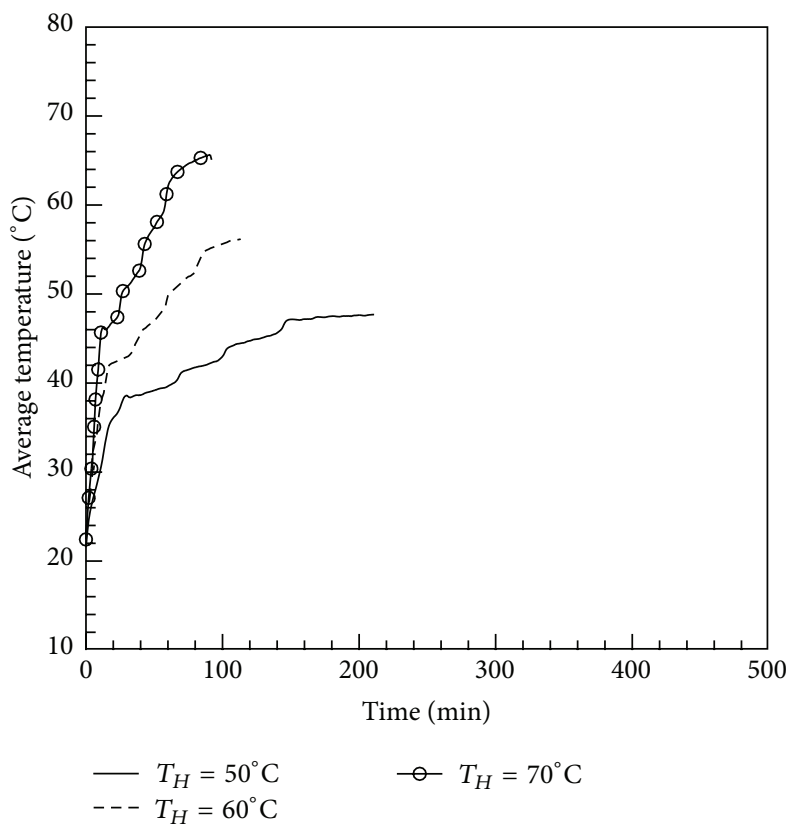

(b)

FIgURE 5: Comparison of average temperature profile in the PCM at various hot inlet HTF temperatures $\left(T_{H}\right)$ in charging process: (a) bared tube heat exchanger; (b) finned-tube heat exchanger.

at $0.6 \mathrm{~L} / \mathrm{min}$. Moreover the consequences of the flow rate variation are studied. Four flow rates are selected $(0.2,0.4$, 0.6 , and $1.6 \mathrm{~L} / \mathrm{min}$ ) using $T_{H}$ for all varying flow rates is set at $60^{\circ} \mathrm{C}$ in charging test and $T_{C}$ is $10^{\circ} \mathrm{C}$ in discharging tests.

2.3. Uncertainty Analysis. Overall uncertainty in the results of experiments depends on the square uncertainty of every variable. Estimating the uncertainty in the present experiment was determined by the equation presented by Kline and McClintock [36]. The accuracy values of the instruments employed in the setup lab are $0.1^{\circ} \mathrm{C}, 0.1^{\circ} \mathrm{C}$, and $0.02 \mathrm{~L} / \mathrm{min}$, respectively, for the K-type thermocouple, Jumo data logger, and Rotameter. Uncertainty of experimental instantaneous power and the cumulative amounts are estimated to be about $\pm 4.0 \%$.

2.4. Flow Regime. The two main input variables of this experiment are temperature and flow rate. Since the flow section is constant, as the flow rate varies, the velocity and consequently the Reynolds number change. On the other hand the fact that viscosity and density of the HTF are functions of temperature signifies that Reynolds number is function of temperature. Therefore these two parameters are critical parameters for Reynolds number estimation and associated flow regime. In Table 2 Reynolds number values are estimated for different flow rates and temperatures.

The colored cells refer to the inputs applied in the experiment. Since the critical Reynolds number for a flow inside tube is 2300 , values above this number mean the flow is turbulent, whereas less values lead to laminar flow. It can be inferred from the table that, as far as mass flow rates are 0.2 , 0.4 , and 0.6, the flow regime is laminar. But when the flow rate reaches to 1.6 , flow regime becomes turbulent.

\section{Results and Discussion}

Several experiments are conducted to check the repeatability of the results. The repeatability of the experiment is conducted for $T_{H}=60^{\circ} \mathrm{C}$ using a flow rate of $0.6 \mathrm{~L} / \mathrm{min}$. Figures 4(a) and 4(b) show PCM temperature profiles and inlet-outlet water temperature difference profiles for three repetitions of a charge process. A good repeatability is observed.

The average temperature was calculated from twelve thermocouples embedded at locations categorized A, B, C, D.

Figures 5(a) and 5(b) show the average temperature variation for simple heat exchanger and finned-tube heat exchanger at three values of $T_{H}=50^{\circ} \mathrm{C}, 60^{\circ} \mathrm{C}, 70^{\circ} \mathrm{C}$ and at a constant flow rate of $0.6 \mathrm{~L} / \mathrm{min}$. The results show that, by increasing $T_{H}$, the PCM average temperature increases which is due to increase of temperature gradient between hot water and PCM.

Increasing $T_{H}$ has a noticeable effect on melting time. Although, as mentioned, utilizing fins reduces the melting time, increasing $T_{H}$ influences both simple and finned- tubes almost to the same degree. To clarify the expression, for simple heat exchanger, the temperature increase initially from 50 to 60 and then to 70 leads to a melting time decrease from 429 to 250 and then to 177 min which means $58 \%$ melting time reduction. Presence of fins leads to similar reduction ratio, namely, from 211 to 121 and then $92 \mathrm{~min}$. 


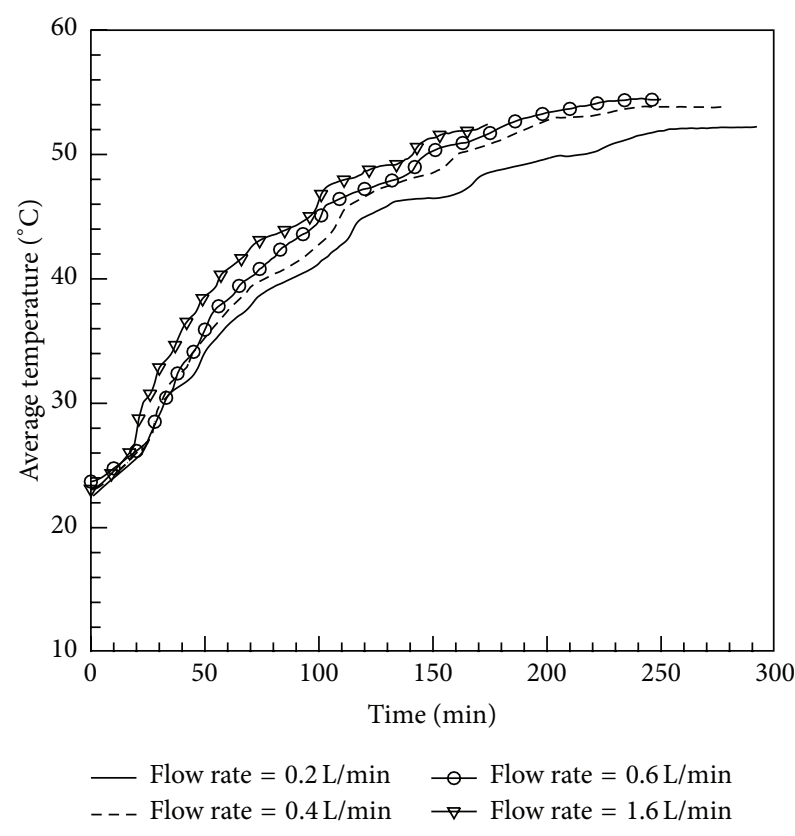

(a)

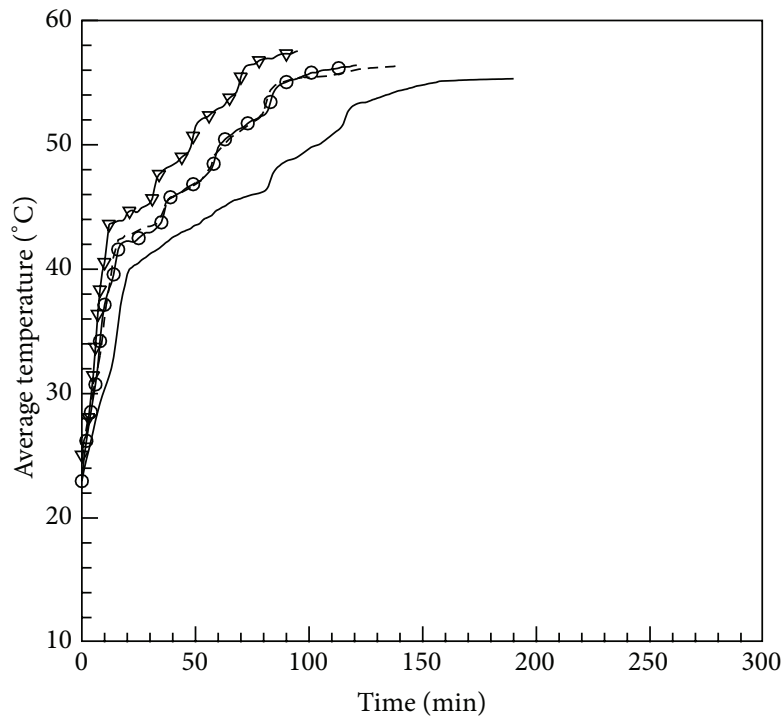

- Flow rate $=0.2 \mathrm{~L} / \mathrm{min} \quad-$ Flow rate $=0.6 \mathrm{~L} / \mathrm{min}$

(b)

FIGURE 6: Comparison of average temperature profile in the PCM at various mass flow rates in charging process: (a) simple heat exchanger; (b) finned-tube heat exchanger.

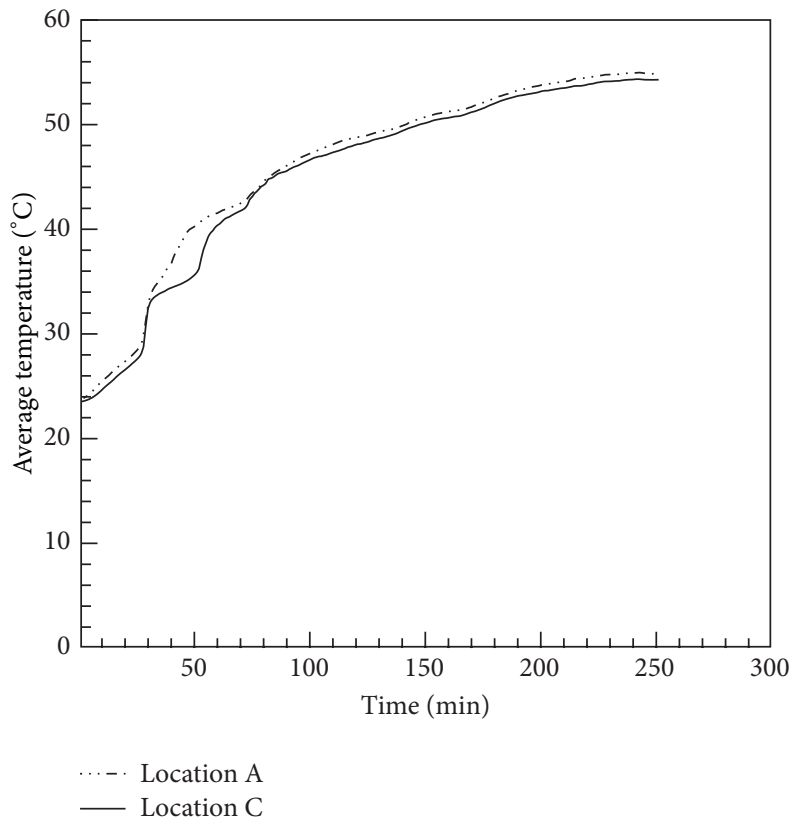

(a)

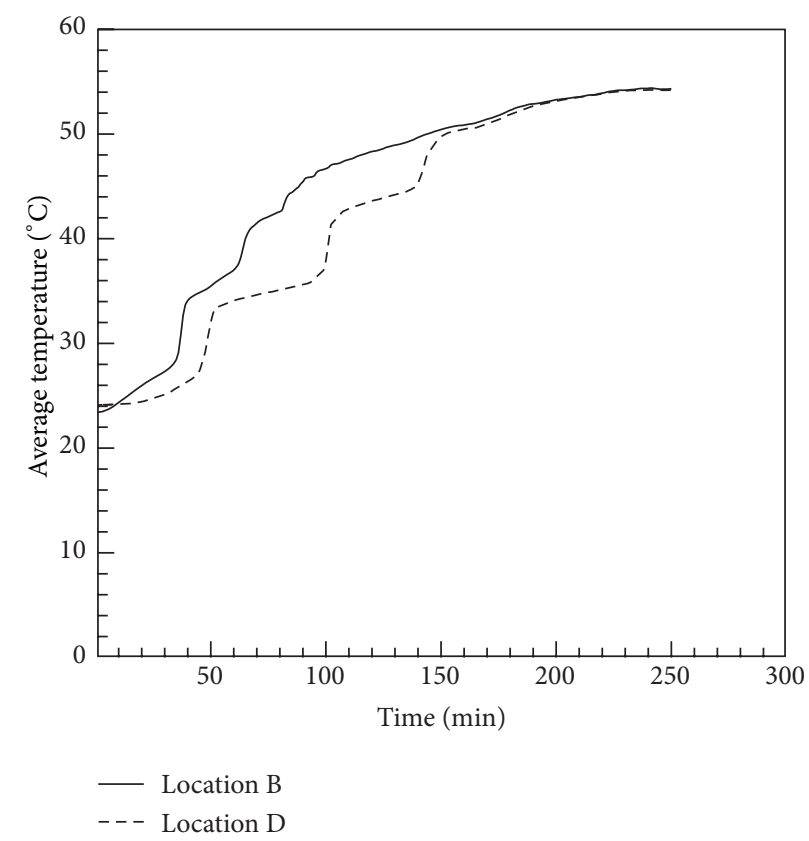

(b)

FIGURE 7: Comparison of average temperature profile in simple heat exchanger in two directions: (a) length; (b) depth.

The effect of various flow rates on the average temperature profile during melting process for two heat exchangers is shown in Figures 6(a) and 6(b).

All the experiments were undertaken at a constant $T_{H}$ of $60^{\circ} \mathrm{C}$ for mass flow rate values of $0.2,0.4,0.6$, and $1.6 \mathrm{~L} / \mathrm{min}$. As can be seen, changing mass flow rate in laminar flow affects melting time less than similar change in temperature. For example, comparing Figures 6(a) and 5(a), one can observe that as the flow rate increases from 0.2 to 0.6 , the melting time decreases from 292 to $250 \mathrm{~min}$, while this increase in $T_{H}$ leads to 429 to 177 min melting time reduction.

While as expected results show when turbulent regime is conducted, at mass flow rate of $1.6 \mathrm{~L} / \mathrm{min}$, melting time varies significantly for simple heat exchanger however for the 


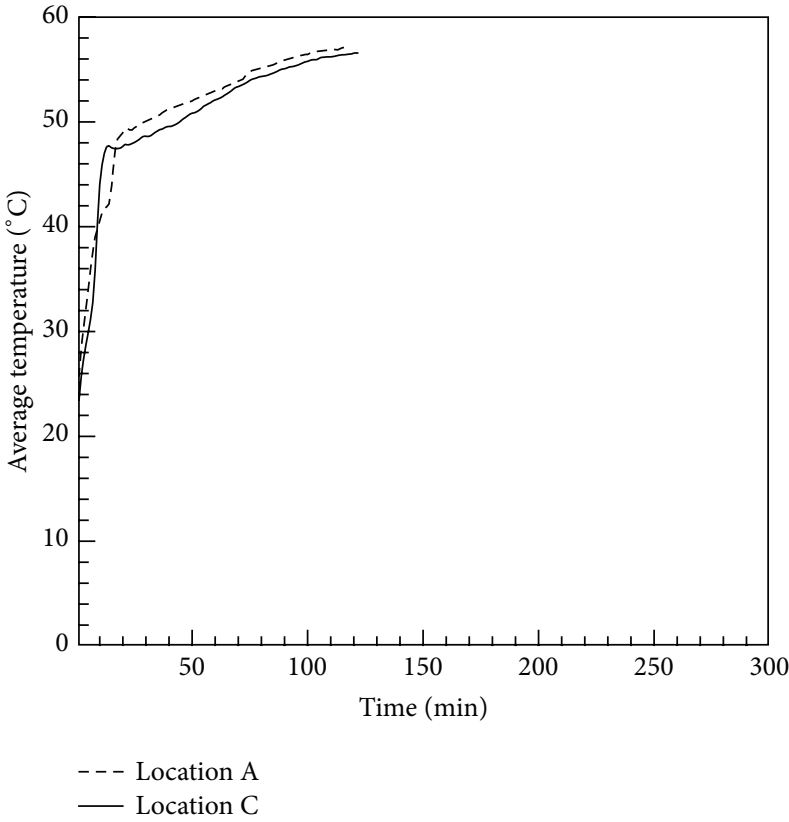

(a)

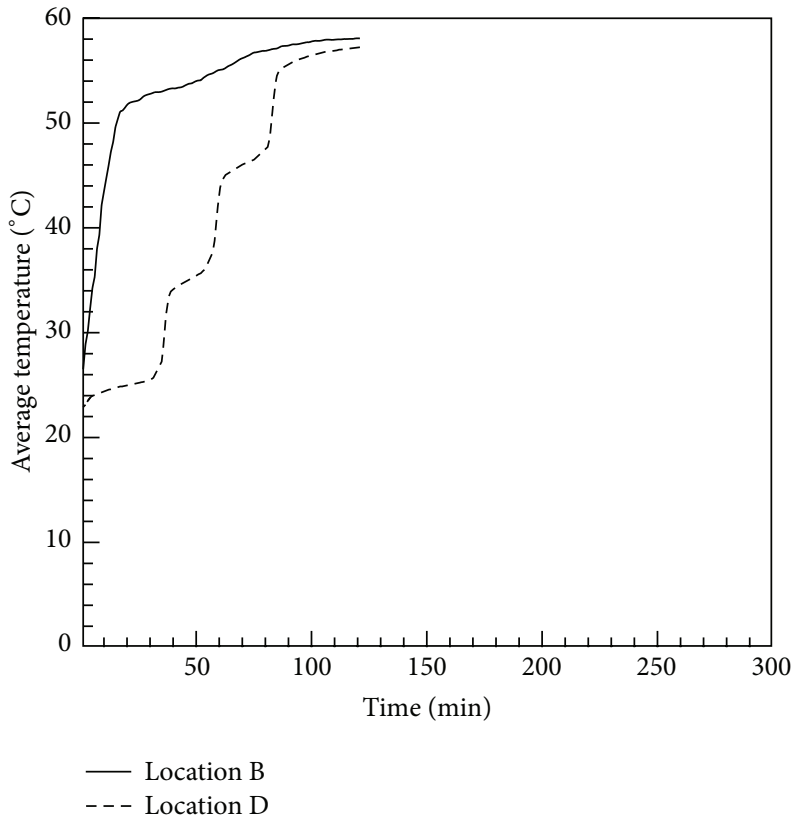

(b)

Figure 8: Comparison of average temperature profile in finned-tube heat exchanger in two directions: (a) length; (b) depth.

TABLE 2: Reynolds numbers for different flow rates and temperature values.

\begin{tabular}{lcccc}
\hline & & \multicolumn{3}{c}{ Inlet HTF temperature } \\
& & $\mathbf{5 0}$ & $\mathbf{6 0}$ & $\mathbf{7 0}$ \\
\hline \multirow{3}{*}{ Flow rate } & $\mathbf{0 . 2}$ & 433 & 507 & 586 \\
& $\mathbf{0 . 4}$ & 866 & 1015 & 1173 \\
& $\mathbf{0 . 6}$ & 1299 & 1522 & 1759 \\
4692 \\
\hline
\end{tabular}

The italic cells refer to the inputs applied in the experiment. Since the critical Reynolds number for a flow inside tube is 2300 , values above this number mean the flow is turbulent, whereas less values lead to laminar flow. It can be inferred from the table that as far as mass flow rates are $0.2,0.4$, and 0.6 , the flow regime is laminar. But when the flow rate reaches to 1.6 flow regime becomes turbulent.

finned-tube heat exchanger, similar to $T_{H}$ s, variation of mass flow rate has minor effect on melting time.

Figures 7(a) and 7(b) show a comparison of average PCM temperatures at locations $\mathrm{A}$ and $\mathrm{C}$ and locations $\mathrm{B}$ and $\mathrm{D}$ versus time, respectively. The results reveal that, for the simple case, temperature difference at locations $\mathrm{B}$ and $\mathrm{D}$ is higher than temperature difference at locations $\mathrm{A}$ and $\mathrm{C}$.

This phenomenon is due to severe variation of liquid fraction and melting front with time in depth of the heat exchanger. As observed, melting front progresses more slowly in depth (at locations B and D) in comparison with length (at locations $\mathrm{A}$ and $\mathrm{C}$ ) which is due to the tube placement at the middle of box.

Another conclusion which one can infer from this figure is that there are some step-like variations in average temperature which is most pronounced for $\mathrm{D}$ region. As each of these regions included 3 thermocouples and each of these thermocouples, based on their position, stat melting at its specific time and D region is the average value of these 3 thermocouples; this steep rise and constant behaviour can be explained. This behaviour is repeated for the finned-tube heat exchanger as well.

Figure 8 shows that, using fins, the rate of the average temperature during melting time, for both directions (depth and length), increases in comparison with the simple heat exchanger.

By observing the variations of the temperature values at locations B and D for finned-tube heat exchanger and comparing it with that of the simple heat exchanger, it is obvious that temperature difference at locations B and D for the finned-tube heat exchanger is higher than that of the simple case. This is because of higher rate of melting front outspread in the middle of box compared to that of near the wall.

Figure 9 illustrates the two heat exchangers for different melting time. Comparing these photos, it can be figured out that employing fins boosts the rate of melting front growth and, as conclusion, the melting region grows more rapidly.

From Figure 10(a), it can be concluded that, increasing $T_{H}$ from $50^{\circ} \mathrm{C}$ to $60^{\circ} \mathrm{C}$, the melting time decreases noticeably, 


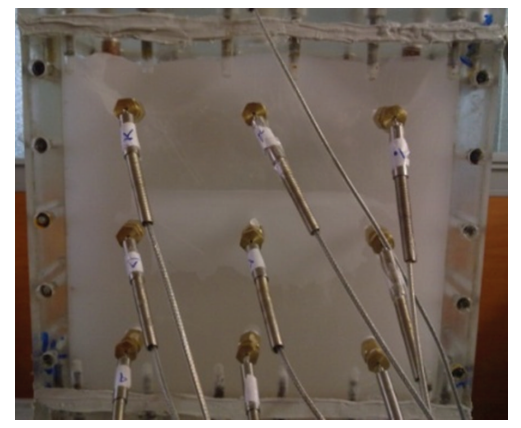

$0 \mathrm{~min}$

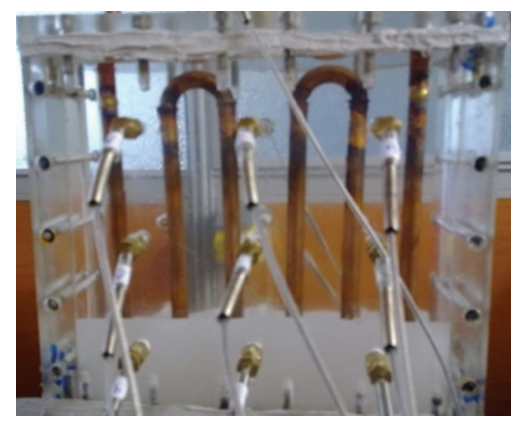

$180 \mathrm{~min}$

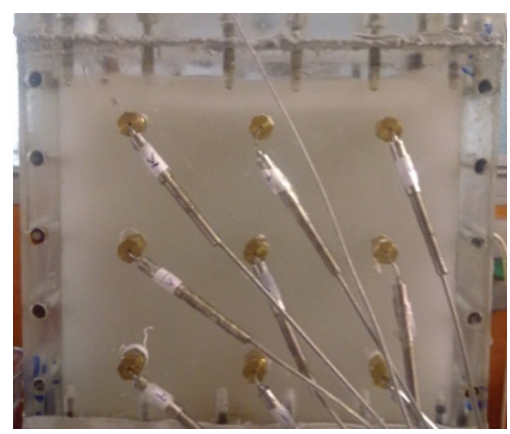

$0 \mathrm{~min}$

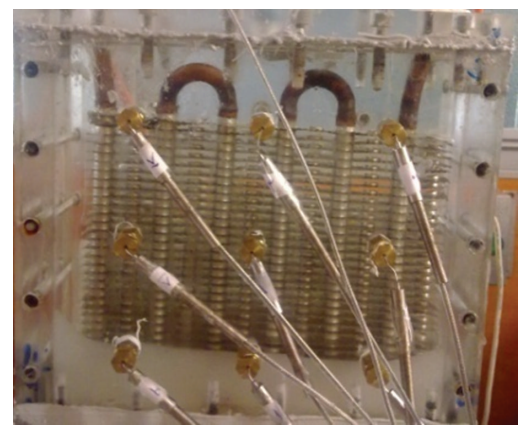

$60 \mathrm{~min}$

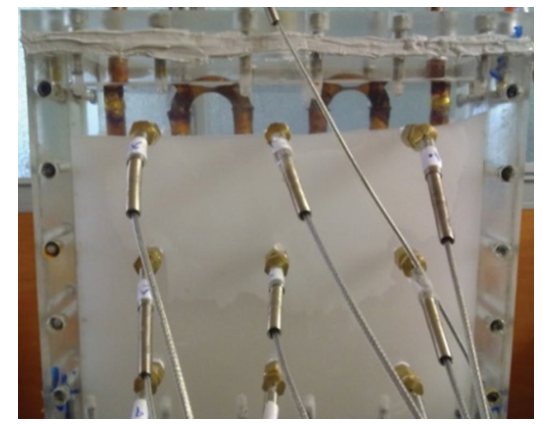

$60 \mathrm{~min}$

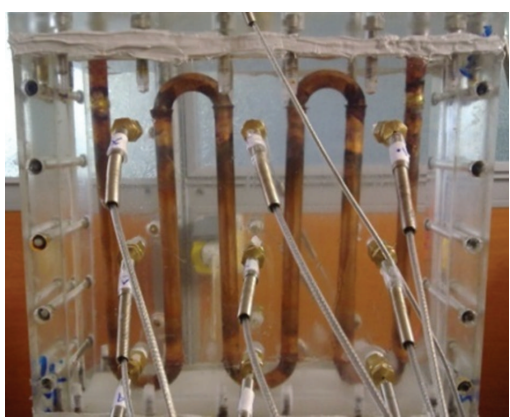

$240 \mathrm{~min}$

(a)

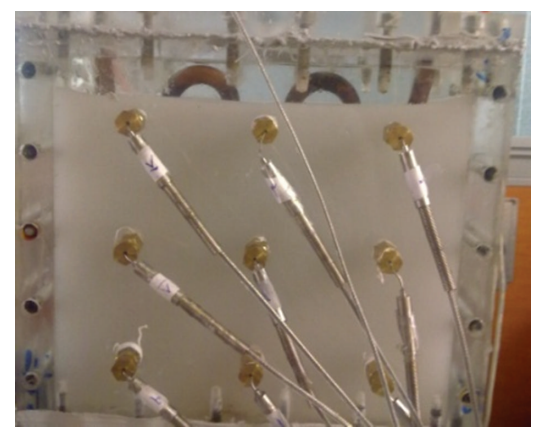

$20 \mathrm{~min}$

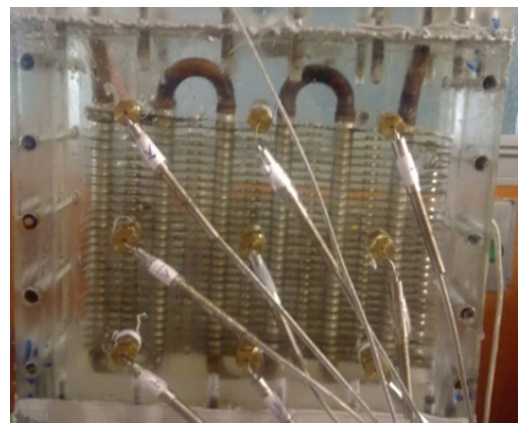

80 min

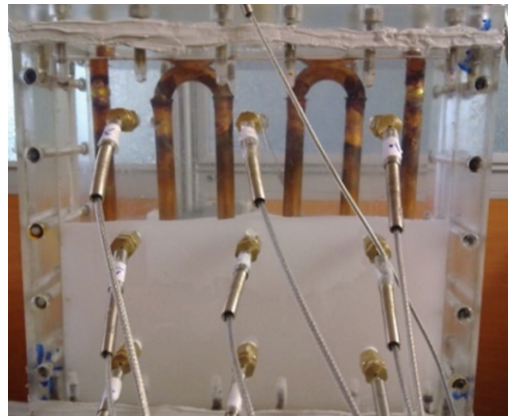

$120 \mathrm{~min}$

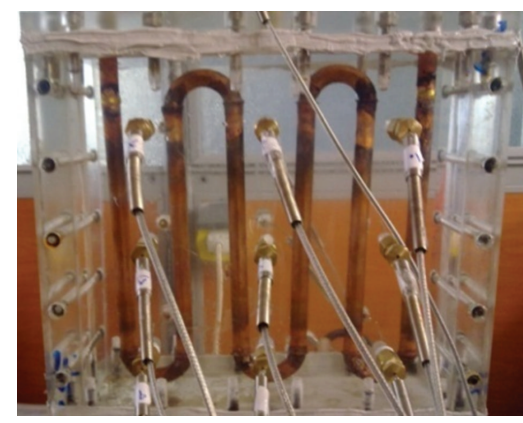

$300 \mathrm{~min}$

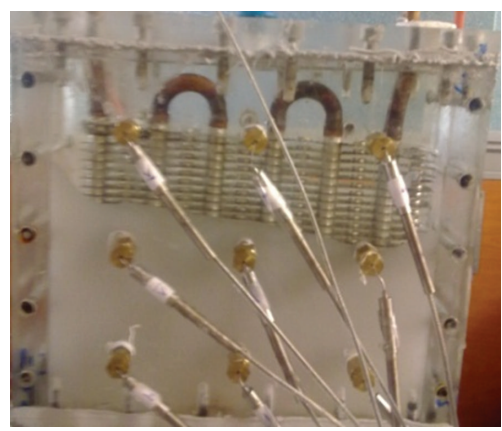

$40 \mathrm{~min}$

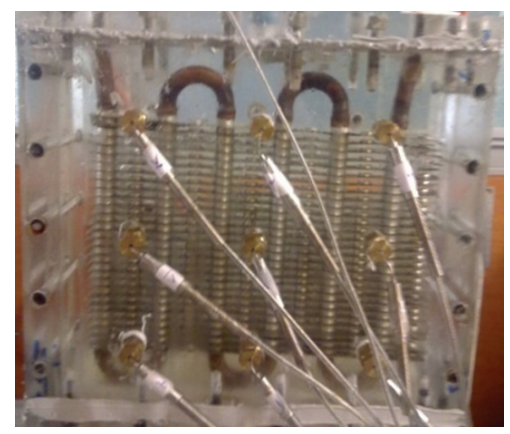

100 min

(b)

FiguRE 9: The melting of phase change material at different times $\left(T_{H}=60^{\circ} \mathrm{C}\right.$, flow rate $\left.=0.6 \mathrm{~L} / \mathrm{min}\right)$ : (a) simple heat exchanger; (b) finnedtube heat exchanger. 


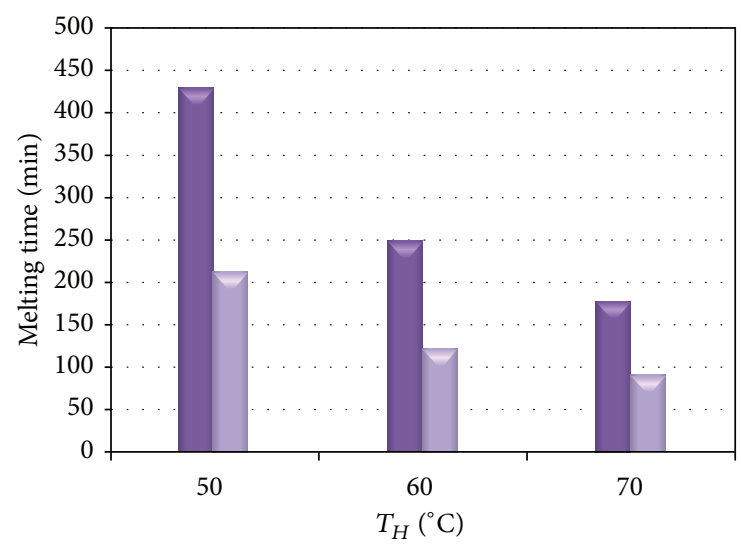

- Simple

- Fin and tube

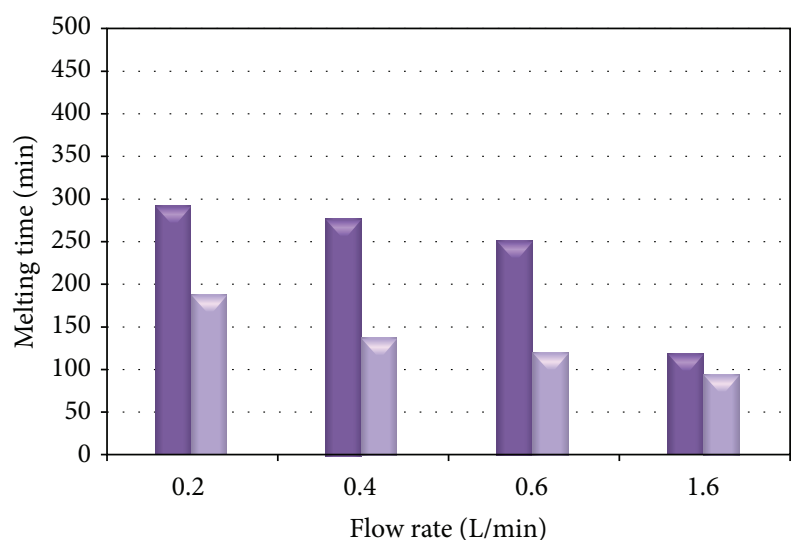

a Simple

Fin and tube

(a)

(b)

Figure 10: Comparison of melting time for the two heat exchangers studied with (a) variation of $T_{H}$ (flow rate $=0.6 \mathrm{~L} / \mathrm{min}$ ); (b) flow rate $\left(T_{H}=60^{\circ} \mathrm{C}\right)$.

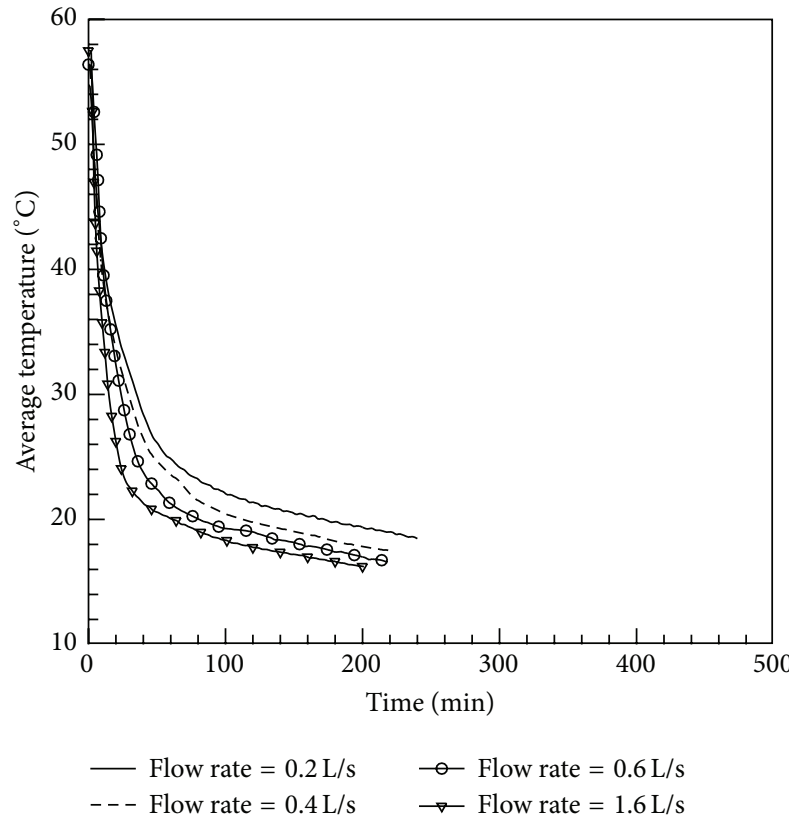

(a)

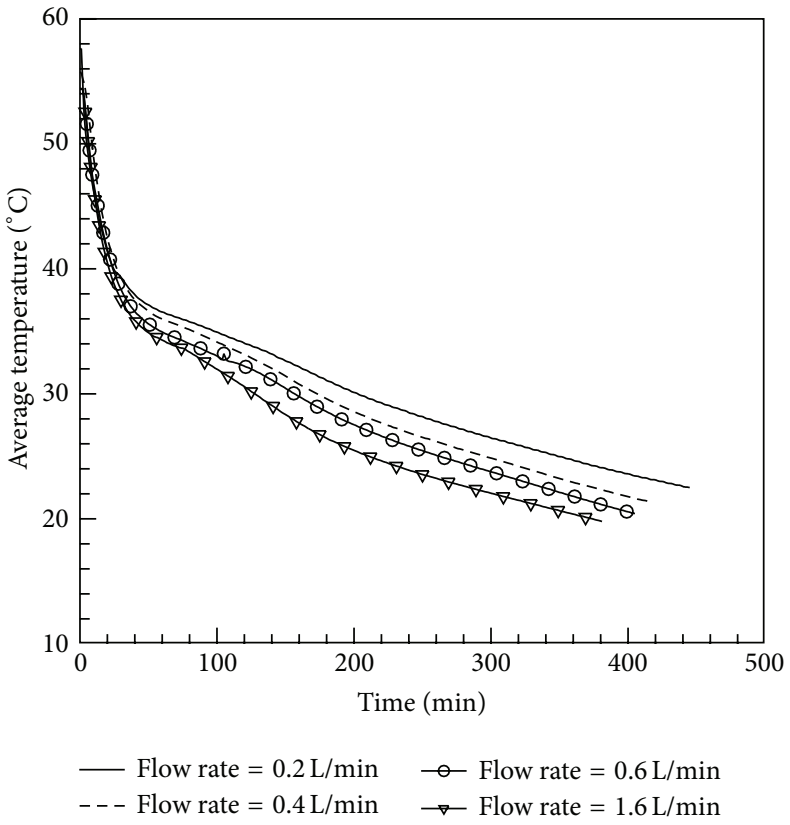

(b)

FIGURE 11: Comparison of average temperature profile in the PCM at various mass flow rates in discharging process: (a) finned-tube heat exchanger; (b) bare tube heat exchanger.

especially for the finned-tube heat exchanger (from 429 to 250 min for simple heat exchanger) while the melting time decrease is less pronounced for more $T_{H}$ raise from $60^{\circ} \mathrm{C}$ to $70^{\circ} \mathrm{C}$, which leads to a decrease from 250 to $177 \mathrm{~min}$ for the simple heat exchanger. Similarly for the finned-tube this increase is less pronounced; for example, increasing $T_{H}$ from 60 to 70 brings about 30 -minute reduction in melting time. On the other hand, Figure 10(b) examines the variation of the HTF flow rate on the melting time. This signifies the fact that as the fluid flow rate increases to 0.6 , for the bare tube heat exchanger, no considerable reduction is detected (292 to $250 \mathrm{~min}$ ). In contrast, an increase of fluid flow from $0.6 \mathrm{~L} / \mathrm{min}$ to $1.6 \mathrm{~L} / \mathrm{min}$, due to the change of the flow regime, the melting time faces an immense decrease to an extent (to $119 \mathrm{~min}$ ) that the exorbitant melting time difference for the heat exchangers almost fades. It is worth noticing that the variation of the fluid flow rate makes a slight change in the melting time (up to $30 \mathrm{~min})$.

Figure 11 shows the trend of the average temperature variation while the cold HTF flow varies for the two heat 
exchangers. Noticing these figures, it is realized that an increase in the mass flow will more intensely lower the average temperature in the discharge process. Comparing temperature profiles of the heat exchangers, the presence of fins lessens the PCM average temperature more severely than the bare tube heat exchanger which leads to the discussed severe melting time reduction. Besides, for the bare tube heat exchanger, a more evident variation in the solidification time occurs when the fluid flow rate varies in comparison with the finned-tube one that can be studied in detail in Figure 11.

\section{Conclusion}

An experimental study has been conducted to investigate the processes of the PCMs (RT35) in a finned-tube heat exchanger and to compare it with a bare heat exchanger. The effect of changing $T_{H}$ and flow rate on the melting and solidification process is investigated. The following results can be found.

(1) Although melting time is an acceptable function of inlet water temperature for which this melting time decreases up to 60 percent, the presence of fins reduces the effect of this variable (this decrease is almost 56 percent for the finned-tube heat exchanger).

(2) For the simple heat exchanger, alteration of the flow regime from laminar to turbulent lowers melting time more than 52 percent.

(3) Comparison of different local temperature values is a conceptual method to understand the behavior of melting and solidification processes.

(4) The average temperature increases more rapidly when enhanced tubes are employed.

(5) The effect of melting time decrease due to inlet water temperature increase differs for varying temperature ranges; an increase from $50^{\circ} \mathrm{C}$ to $60^{\circ} \mathrm{C}$ diminishes the melting time and up to 42 percent which is more substantial than $60^{\circ} \mathrm{C}$ to $70^{\circ} \mathrm{C}$ that leads to about 26 percent melting time reduction.

(6) The flow rate influences the solidification time. This influence is more extensive for the bare tube heat exchanger.

\section{Nomenclatures}

\author{
$c_{P}$ : Specific heat capacity \\ $h$ : Sensible enthalpy \\ $k$ : Thermal conductivity \\ L: Latent heat \\ T: Temperature.
}

\section{Greek Symbols}

$\beta$ : Volumetric expansion coefficient

$\rho$ : Density.

\section{Subscripts}

$H: \quad$ Hot water

C: $\quad$ Cold water

Liquid: PCM at liquid state

Solid: PCM at solid state.

\section{Conflict of Interests}

The authors declare that there is no conflict of interests regarding the publication of this paper.

\section{References}

[1] R. Velraj, R. V. Seeniraj, B. Hafner, C. Faber, and K. Schwarzer, "Heat transfer enhancement in a latent heat storage system," Solar Energy, vol. 65, no. 3, pp. 171-180, 1999.

[2] R. Velraj, R. V. Seeniraj, B. Hafner, C. Faber, and K. Schwarzer, "Experimental analysis and numerical modelling of inward solidification on a finned vertical tube for a latent heat storage unit," Solar Energy, vol. 60, no. 5, pp. 281-290, 1997.

[3] K. A. R. Ismail, C. L. F. Alves, and M. S. Modesto, "Numerical and experimental study on the solidification of PCM around a vertical axially finned isothermal cylinder," Applied Thermal Engineering, vol. 21, no. 1, pp. 53-77, 2001.

[4] E. M. Sparrow, E. D. Larson, and J. W. Ramsey, "Freezing on a finned tube for either conduction-controlled or naturalconvection-controlled heat transfer," International Journal of Heat and Mass Transfer, vol. 24, no. 2, pp. 273-284, 1981.

[5] U. Stritih, "An experimental study of enhanced heat transfer in rectangular PCM thermal storage," International Journal of Heat and Mass Transfer, vol. 47, no. 12-13, pp. 2841-2847, 2004.

[6] A. Trp, "An experimental and numerical investigation of heat transfer during technical grade paraffin melting and solidification in a shell-and-tube latent thermal energy storage unit," Solar Energy, vol. 79, no. 6, pp. 648-660, 2005.

[7] A. Trp, K. Lenic, and B. Frankovic, "Analysis of the influence of operating conditions and geometric parameters on heat transfer in water-paraffin shell-and-tube latent thermal energy storage unit," Applied Thermal Engineering, vol. 26, no. 16, pp. 1830$1839,2006$.

[8] A. Erek, Z. Ilken, and M. A. Acar, "Experimental and numerical investigation of thermal energy storage with a finned tube," International Journal of Energy Research, vol. 29, no. 4, pp. 283301, 2005.

[9] A. Erek and M. A. Ezan, "Experimental and numerical study on charging processes of an ice-on-coil thermal energy storage system," International Journal of Energy Research, vol. 31, no. 2, pp. 158-176, 2007.

[10] L. C. Chow, J. K. Zhong, and J. E. Beam, “Thermal conductivity enhancement for phase change storage media," International Communications in Heat and Mass Transfer, vol. 23, no. 1, pp. 91-100, 1996.

[11] J. P. Bédécarrats, F. Strub, B. Falcon, and J. P. Dumas, "Phasechange thermal energy storage using spherical capsules: performance of a test plant," International Journal of Refrigeration, vol. 19, no. 3, pp. 187-196, 1996.

[12] J. C. Mulligan, D. P. Colvin, and Y. G. Bryant, "Microencapsulated phase-change material suspensions for heat transfer in spacecraft thermal systems," Journal of Spacecraft and Rockets, vol. 33, no. 2, pp. 278-284, 1996. 
[13] J. M. Marín, B. Zalba, L. F. Cabeza, and H. Mehling, "Improvement of a thermal energy storage using plates with paraffingraphite composite," International Journal of Heat and Mass Transfer, vol. 48, no. 12, pp. 2561-2570, 2005.

[14] L. F. Cabeza, H. Mehling, S. Hiebler, and F. Ziegler, "Heat transfer enhancement in water when used as PCM in thermal energy storage," Applied Thermal Engineering, vol. 22, no. 10, pp. 1141-1151, 2002.

[15] H. Mehling, S. Hiebler, and F. Ziegler, "Latent heat storage using a PCM-graphite composite material," in Proceedings of the 8th International Conference on Thermal Energy Storage (Terrastock '00), pp. 375-80, Stuttgart, Germany, 2000.

[16] X. Py, R. Olives, and S. Mauran, "Paraffin/porous-graphitematrix composite as a high and constant power thermal storage material," International Journal of Heat and Mass Transfer, vol. 44, no. 14, pp. 2727-2737, 2001.

[17] M. Xiao, B. Feng, and K. Gong, "Thermal performance of a high conductive shape-stabilized thermal storage material," Solar Energy Materials \& Solar Cells, vol. 69, no. 3, pp. 293-296, 2001.

[18] W. Wang, X. Yang, Y. Fang, and J. Ding, "Preparation and performance of form-stable polyethylene glycol/silicon dioxide composites as solid-liquid phase change materials," Applied Energy, vol. 86, no. 2, pp. 170-174, 2009.

[19] W. Wang, X. Yang, Y. Fang, J. Ding, and J. Yan, "Enhanced thermal conductivity and thermal performance of form-stable composite phase change materials by using $\beta$-Aluminum nitride," Applied Energy, vol. 86, no. 7-8, pp. 1196-1200, 2009.

[20] M. J. Hosseini, A. A. Ranjbar, K. Sedighi, and M. Rahimi, "A combined experimental and computational study on the melting behavior of a medium temperature phase change storage material inside shell and tube heat exchanger," International Communications in Heat and Mass Transfer, vol. 39, no. 9, pp. 1416-1424, 2012.

[21] F. Agyenim, P. Eames, and M. Smyth, "Heat transfer enhancement in medium temperature thermal energy storage system using a multitube heat transfer array," Renewable Energy, vol. 35, no. 1, pp. 198-207, 2010.

[22] F. Agyenim, P. Eames, and M. Smyth, "Experimental study on the melting and solidification behaviour of a medium temperature phase change storage material (Erythritol) system augmented with fins to power a $\mathrm{LiBr} / \mathrm{H}_{2} \mathrm{O}$ absorption cooling system," Renewable Energy, vol. 36, no. 1, pp. 108-117, 2011.

[23] F. Agyenim and N. Hewitt, "The development of a finned phase change material (PCM) storage system to take advantage of offpeak electricity tariff for improvement in cost of heat pump operation," Energy and Buildings, vol. 42, no. 9, pp. 1552-1560, 2010.

[24] F. Agyenim, P. Eames, and M. Smyth, "A comparison of heat transfer enhancement in a medium temperature thermal energy storage heat exchanger using fins," Solar Energy, vol. 83, no. 9, pp. 1509-1520, 2009.

[25] T. K. Sinha and J. P. Gupta, "Solidification in an annulus," International Journal of Heat and Mass Transfer, vol. 25, no. 11, pp. 1771-1773, 1982.

[26] M. A. Ezan, M. Ozdogan, and A. Erek, "Experimental study on charging and discharging periods of water in a latent heat storage unit," International Journal of Thermal Sciences, vol. 50, no. 11, pp. 2205-2219, 2011.

[27] M. Medrano, M. O. Yilmaz, M. Nogués, I. Martorell, J. Roca, and L. F. Cabeza, "Experimental evaluation of commercial heat exchangers for use as PCM thermal storage systems," Applied Energy, vol. 86, no. 10, pp. 2047-2055, 2009.

[28] M. Akgun, O. Aydin, and K. Kaygusuz, "Thermal energy storage behavior of a paraffin during melting and solidification," Energy Sources A: Recovery, Utilization and Environmental Effects, vol. 29, no. 14, pp. 1315-1326, 2007.

[29] M. Akgün, O. Aydin, and K. Kaygusuz, "Experimental study on melting/solidification characteristics of a paraffin as PCM," Energy Conversion and Management, vol. 48, no. 2, pp. 669-678, 2007.

[30] J. L. Zeng, L. X. Sun, F. Xu et al., "Study of a PCM based energy storage system containing Ag nanoparticles," Journal of Thermal Analysis and Calorimetry, vol. 87, no. 2, pp. 371-375, 2007.

[31] A. A. Ranjbar, S. Kashani, S. F. Hosseinizadeh, and M. Ghanbarpour, "Numerical heat transfer studies of a latent heat storage system containing nano-enhanced phase change material," Thermal Science, vol. 15, no. 1, pp. 169-181, 2011.

[32] M. Rahimi, A. A. Ranjbar, M. J. Hosseini, and M. Abdollahzadeh, "Natural convection of nanoparticle-water mixture near its density inversion in a rectangular enclosure," International Communications in Heat and Mass Transfer, vol. 39, no. 1, pp. 131-137, 2012.

[33] C. J. Ho and J. Y. Gao, "Preparation and thermophysical properties of nanoparticle-in-paraffin emulsion as phase change material," International Communications in Heat and Mass Transfer, vol. 36, no. 5, pp. 467-470, 2009.

[34] A. Elgafy and K. Lafdi, "Effect of carbon nanofiber additives on thermal behavior of phase change materials," Carbon, vol. 43, no. 15, pp. 3067-3074, 2005.

[35] E.-B. S. Mettawee and G. M. R. Assassa, "Thermal conductivity enhancement in a latent heat storage system," Solar Energy, vol. 81, no. 7, pp. 839-845, 2007.

[36] S. J. Kline and F. A. McClintock, "Describing uncertainties in single-sample experiments," Mechanical Engineering, vol. 75, no. 1, pp. 3-8, 1953. 

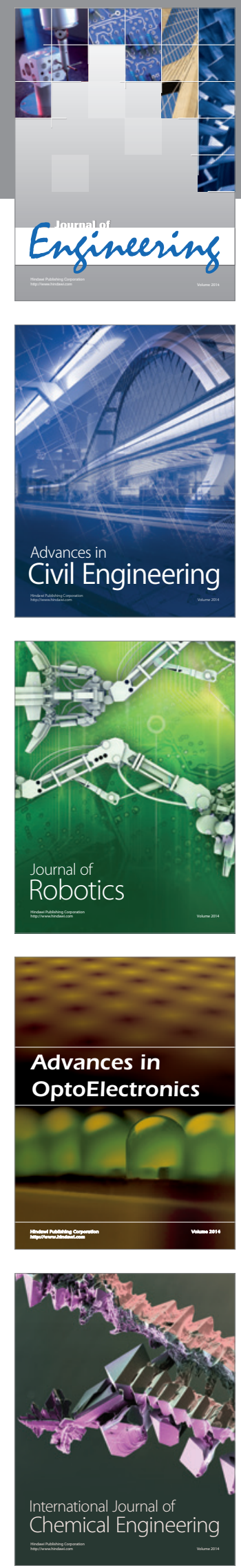

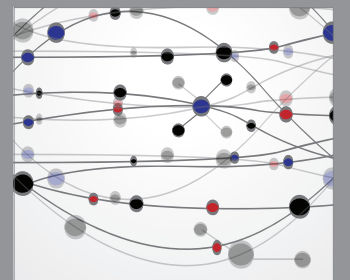

The Scientific World Journal
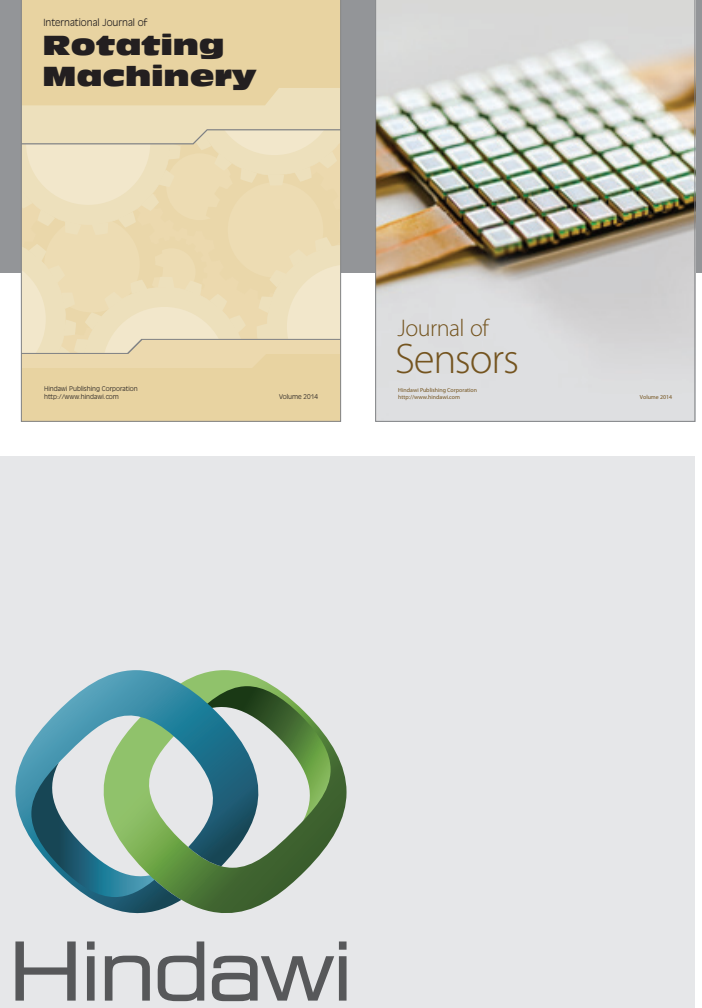

Submit your manuscripts at http://www.hindawi.com
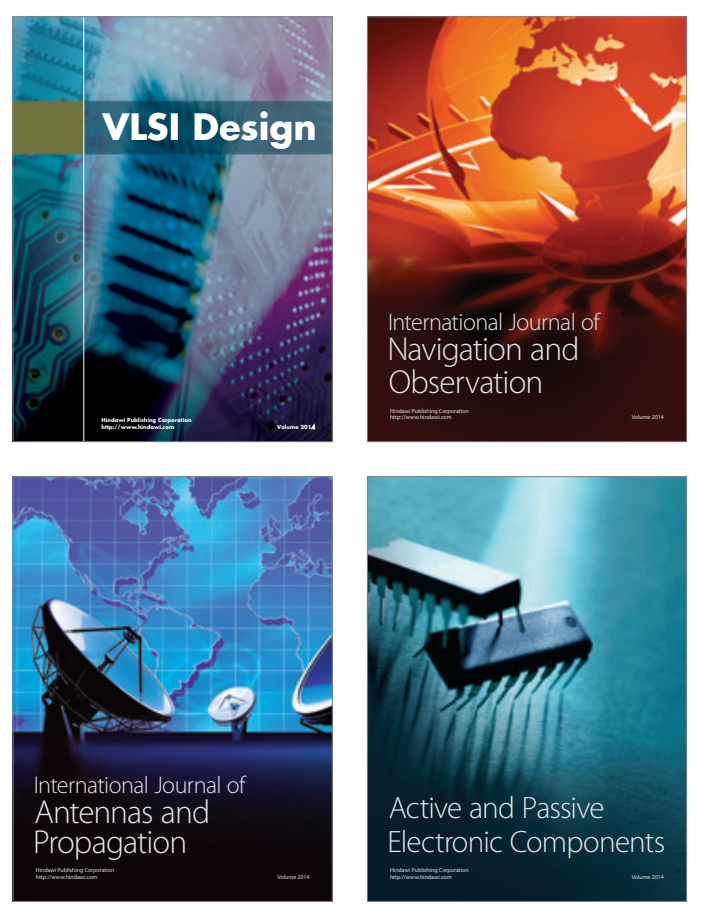
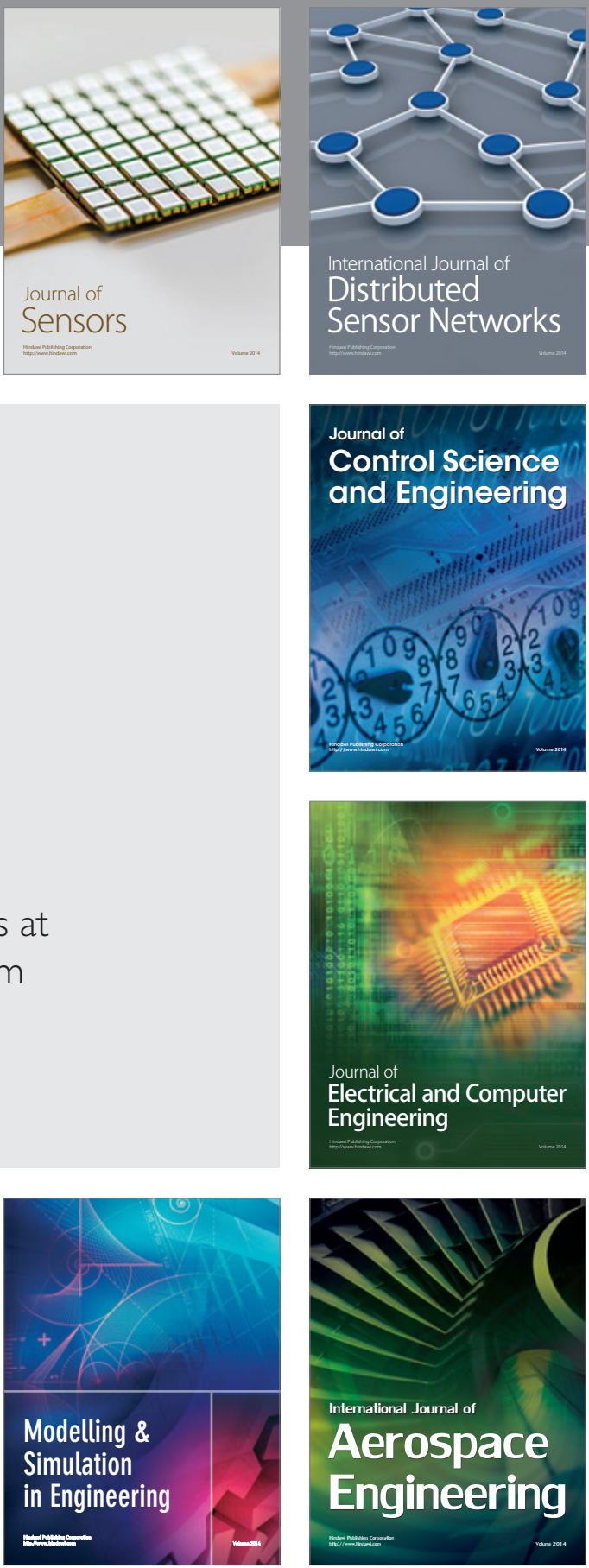

Journal of

Control Science

and Engineering
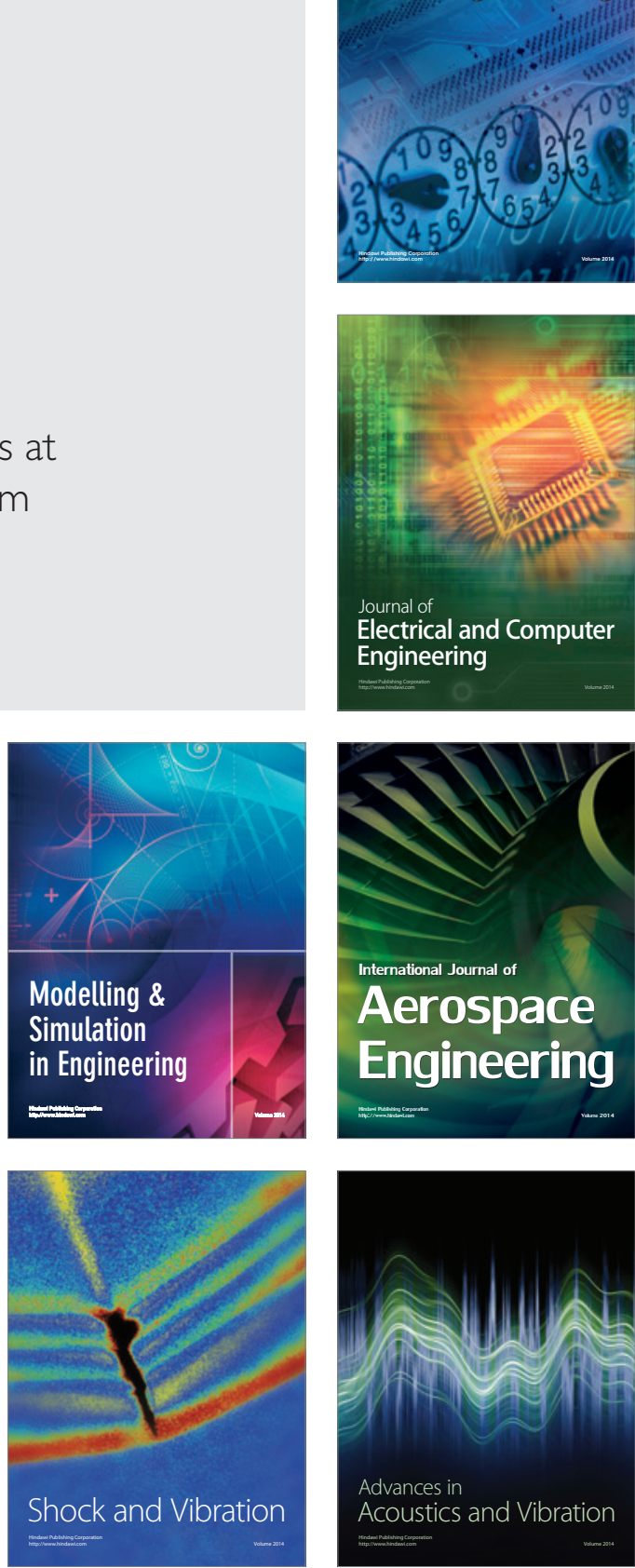